\title{
STUDIES ON NEW PHOSPHONIC ACID ANTIBIOTICS \\ III. ISOLATION AND CHARACTERIZATION OF FR-31564, FR-32863 AND FR-33289
}

\author{
Masakuni Okuhara, Yoshio Kuroda, Toshio Goto, Masanori Okamoto, Hiroshi Terano, \\ Masanobu Kohsaka, Hatsuo Aoki and Hiroshi Imanaka \\ Research Laboratories, Fujisawa Pharmaceutical Co., Ltd., \\ Osaka, Japan
}

(Received for publication September 6, 1979)

\begin{abstract}
Three phosphonic acid antibiotics were found to be produced in the fermentation broths of Streptomyces. FR-31564 and FR-32863 were produced by Streptomyces lavendulae. FR33289 was produced by a strain of Streptomyces, identified as Streptomyces rubellomurinus subsp. indigoferus. They are distinct from, but resemble FR-900098 which was reported in our preceding paper, in their chemical and biological characteristics.
\end{abstract}

In our preceding paper, we described biological and physico-chemical characterization of a new phosphonic acid antibiotics, FR-900098 ${ }^{1}$. The antibiotic has been identified chemically as 3-(N-acetyl$\mathrm{N}$-hydroxy)aminopropylphosphonic acid $^{2}$. Our screening system enabled us to isolate three new phosphonic acid antibiotics, which were distinct from, but resemble FR-900098. This paper describes fermentation and isolation procedures for FR-31564, FR-32863 and FR-33289 and characterizes them by their physico-chemical and biological properties.

\section{Fermentation and Assay Studies}

Taxonomic studies of the producing strains are described in the preceding paper ${ }^{3)}$. Strain No. 8006, which was identified as Streptomyces lavendulae, produced two new antibiotics, FR-31564 and FR-32863. Strain No. 24, which was identified as a new subspecies of Streptomyces rubellomurinus, and was named Streptomyces rubellomurinus subsp. indigoferus, produced a new antibiotic, FR-33289 along with FR-900098. The antibiotics were produced by submerged fermentation in shaker flasks or stainless steel fermentors with medium listed in Table 1. Fermentation conditions were essentially the same as described previously ${ }^{1}$.

Presence of antibiotics in the culture broth was monitored by the use of disc-agar diffusion assay with a mutant of Pseudomonas aeruginosa, Ps-III or Enterobacter cloacae 10-19C as the assay organisms. The antibiotics were detected on chromatograms by bioautography on agar seeded with Ps-III. Chromatographic properties are presented in Table 2. The antibiotics may be visualized by spraying with ferric chloride solution; brown color develops on warming.

Isolation and purification procedures analogous to those mentioned in the preceding paper ${ }^{1)}$ enabled us to separate the three active substances into purified samples.

\section{Physico-chemical Properties}

The physico-chemical properties of the three antibiotics are shown in Table 3. FR-31564, FR- 
Table 1. Media used for production of FR-31564, FR-32863 and FR-33289.

\begin{tabular}{ll|ll}
\hline \multicolumn{1}{c}{ Seed medium } & \multicolumn{2}{c}{ Production medium } \\
\hline Potato starch & $1 \%$ & Methyl oleate & $3 \%$ \\
Glycerin & 1 & Cotton seed meal & 1 \\
Cotton seed meal & 1 & Wheat germ & 1 \\
Dried yeast & 1 & Corn steep liquor & 0.5 \\
& & Dried yeast & 0.5 \\
& & $\mathrm{KH}_{2} \mathrm{PO}_{4}$ & 1 \\
& $\mathrm{Na}_{2} \mathrm{HPO}_{4} \cdot 12 \mathrm{H}_{2} \mathrm{O}$ & 1 \\
\hline
\end{tabular}

Table 2. Chromatographic properties of FR-900098, FR-33289, FR-31564 and FR-32863.

\begin{tabular}{|c|c|c|c|c|}
\hline \multirow{2}{*}{ System } & \multicolumn{4}{|c|}{$\mathrm{Rf}$} \\
\hline & $\begin{array}{c}\text { FR- } \\
900098\end{array}$ & $\begin{array}{c}\text { FR- } \\
33289\end{array}$ & $\begin{array}{l}\text { FR- } \\
31564\end{array}$ & $\begin{array}{c}\text { FR- } \\
32863\end{array}$ \\
\hline $\begin{array}{l}\text { T.1.c. cellulose } \\
\text { (Eastman } \\
\text { Kodak Co.) } \\
n \text {-propanol - } \\
\text { water }(3: 2)\end{array}$ & 0.73 & 0.65 & 0.60 & 0.58 \\
\hline
\end{tabular}

Table 3. Physico-chemical properties of FR-33289, FR-31564 and FR-32863.

\begin{tabular}{|c|c|c|c|c|}
\hline & & FR-33289 & FR-31564 & FR-32863 \\
\hline \multicolumn{2}{|c|}{ Appearance } & White powder & Colorless crystal & Colorless crystal \\
\hline \multicolumn{2}{|c|}{ m.p. $\left({ }^{\circ} \mathrm{C}\right)($ dec. $)$} & & $189 \sim 191$ & $176 \sim 180$ \\
\hline Anal. & $\begin{array}{l}\text { Obs. } \\
\text { Calc. }\end{array}$ & $\begin{array}{ccccc}\mathrm{C} & \mathrm{H} & \mathrm{N} & \mathrm{P} & \mathrm{Na} \\
25.10, & 4.81, & 5.63, & 12.58, & 9.13 \\
25.53, & 4.68, & 5.96, & 13.19, & 9.79\end{array}$ & 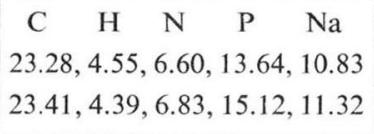 & $\begin{array}{ccccc}\mathrm{C} & \mathrm{H} & \mathrm{N} & \mathrm{P} & \mathrm{K} \\
21.87, & 3.42, & 6.40, & 15.13, & 17.01 \\
21.92, & 3.22, & 6.39, & 14.13,17.81\end{array}$ \\
\hline \multicolumn{2}{|c|}{ Mol. Form. } & $\mathrm{C}_{5} \mathrm{H}_{11} \mathrm{NO}_{6} \mathrm{PNa}$ & $\mathrm{C}_{4} \mathrm{H}_{9} \mathrm{NO}_{5} \mathrm{PNa}$ & $\mathrm{C}_{4} \mathrm{H}_{7} \mathrm{NO}_{5} \mathrm{PK}$ \\
\hline \multicolumn{2}{|c|}{ IR (Nujol, $\mathrm{cm}^{-1}$ ) } & $\begin{array}{l}3200,2400,1740,1630 \\
1420,1240,1150,1050 \\
965,900\end{array}$ & $\begin{array}{l}3600 \sim 2200,1675,1510 \\
1270,1230,1165,1015 \\
985,920,885\end{array}$ & 1665,1250 \\
\hline \multicolumn{2}{|c|}{$\operatorname{NMR}\left(\mathrm{D}_{2} \mathrm{O}, \delta\right)$} & $\begin{array}{l}1.88(2 \mathrm{H}, \mathrm{d} . \mathrm{d}, \mathrm{J}=6 \text { and } \\
18 \mathrm{~Hz}) \\
2.16(3 \mathrm{H}, \mathrm{s}) \\
3.66 \sim 3.90(2 \mathrm{H}, \mathrm{m}) \\
4.30(1 \mathrm{H}, \mathrm{m})\end{array}$ & 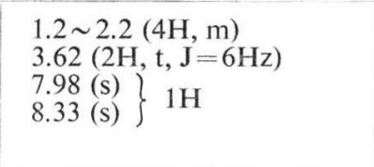 & 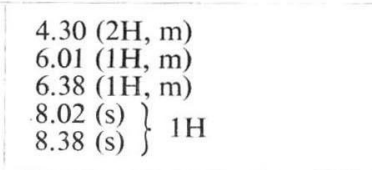 \\
\hline \multicolumn{2}{|c|}{$\begin{array}{l}\text { Paper electrophoresis } \\
\text { Phosphate buffer ( } \mathrm{pH} \\
6.5 \text { ) at } 300 \text { volts, } \\
2 \text { hours }\end{array}$} & $+3 \mathrm{~cm}$ & $+3 \mathrm{~cm}$ & $+3 \mathrm{~cm}$ \\
\hline
\end{tabular}

32863 and FR-33289 are soluble in water, methanol, dimethylsulfoxide and dimethylformamide, but are insoluble in common organic solvents. They move toward anode with phosphate buffer ( $\mathrm{pH}$ $6.5)$ at 300 volts in paper electrophoresis for 2 hours. Titration and mass spectrometry established the molecular formulas presented in Table 3.

Color reactions are as follows: positive in ferric chloride, iodine, potassium permanganate tests, negative in ninhydrin, Ehrlich, Dragendorff and Molisch tests. They have no characteristic ultraviolet absorption. Infrared absorption spectra are shown in Fig. 1 and proton magnetic resonance spectra in Fig. 2.

\section{Biological Properties}

The antibacterial spectra of FR-31564, FR-32863 and FR-33289 were compared with that of FR900098 in Table 4. It is apparent from the data that the three antibiotics resemble each other and FR-900098 in their antibacterial activity. All of them possess rather unusual characteristics in that strength of their antibiotic activity can be arranged in the order, Pseudomonas, Proteus, Salmonella, 
Fig. 1-a. IR spectrum of FR-31564 (nujol).

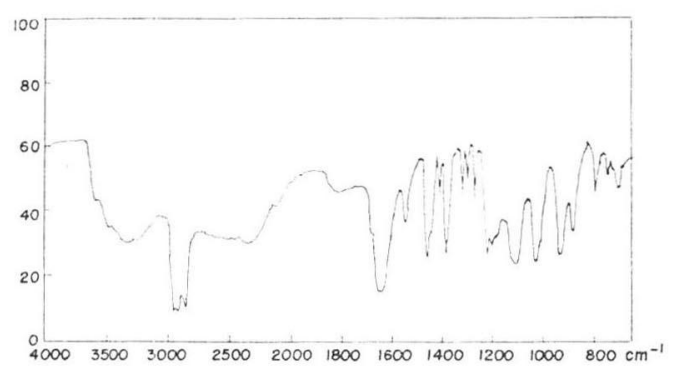

Fig. 1-b. IR spectrum of FR-32863 (nujol).

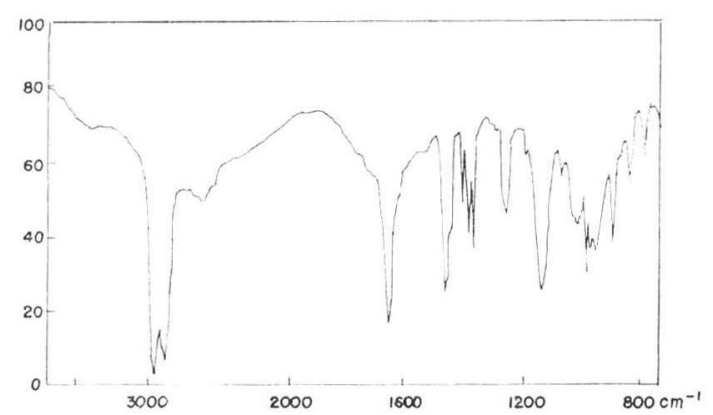

Fig. 1-c. IR spectrum of FR-33289 (nujol).

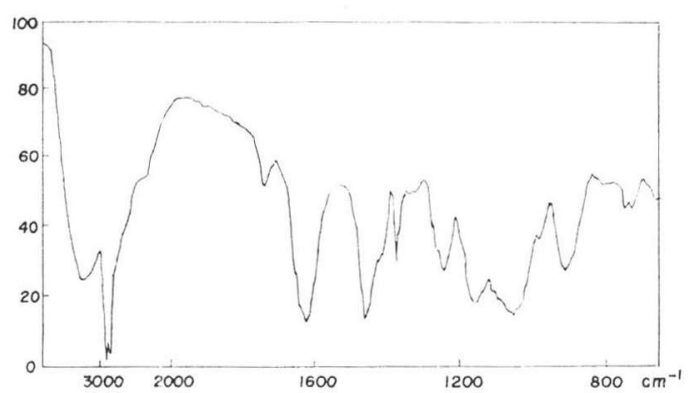

Fig. 2-a. NMR spectrum of FR-31564 $\left(\mathrm{D}_{2} \mathrm{O}\right)$.

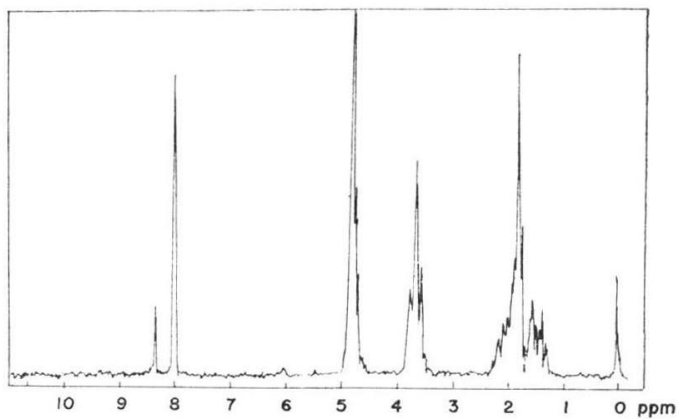

Fig. 2-b. NMR spectrum of FR-32863 ( $\left.\mathrm{D}_{2} \mathrm{O}\right)$.

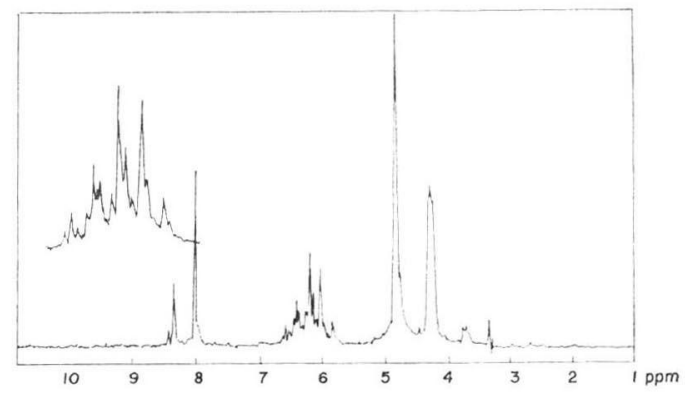

Fig. 2-c. NMR spectrum of FR-33289 ( $\left.\mathrm{D}_{2} \mathrm{O}\right)$.

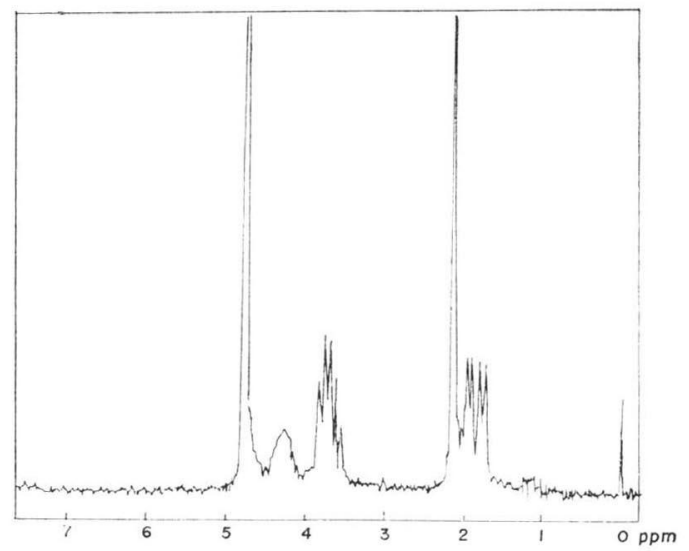

Escherichia coli. They show no inhibitory activity against Staphylococcus aureus at the concentrations tested in this experiment.

A second point which is evident from this table is that FR-31564 and FR-32863 exhibit a similar range of potencies, whereas FR-900098 and FR-33289 appear to have much weaker antibacterial activity.

A series of revertants were derived from Ps. aeruginosa III, selected in vitro for their high level of resistance to FR-900098. The cross resistance patterns of FR-31564, FR-32863 and FR-33289 were measured by the use of these resistant revertants. The results are presented in Table 4 . Cross re- 
Table 4. Antibacterial spectra of FR-900098, FR-33289, FR-31564 and FR-32863.

\begin{tabular}{l|r|r|r|r}
\hline \multicolumn{1}{c|}{ Organism } & \multicolumn{3}{|c}{ MIC $(\mu \mathrm{g} / \mathrm{ml})^{*}$} \\
\cline { 2 - 5 } Staphylococcus aureus FDA 209P & FR-900098 & FR-33289 & FR-31564 & FR-32863 \\
Bacillus subtilis ATCC 6633 & $>800$ & $>400$ & $>100$ & $>100$ \\
Sarcina lutea PCI-1001 & 200 & 400 & 6.25 & 6.25 \\
Klebsiella pneumoniae NCTC-418 & 8 & 400 & 0.1 & 0.2 \\
Shigella flexneri 1a EW 8 & 800 & 400 & 50 & 100 \\
Salmonella typhi O-901 & 8 & 200 & 6.25 & 50 \\
Proteus vulgaris IAM 1025 & 2 & 200 & 0.39 & 0.78 \\
Pseudomonas aeruginosa IAM 1095 & 125 & 400 & 3.13 & 3.13 \\
Escherichia coli NIHJ JC 2 & 250 & 400 & 0.78 & 1.56 \\
Ps III & 400 & 50 & 12.5 & 12.5 \\
Ps III ${ }^{\mathrm{r} * *}$ & 1.6 & 25 & 0.05 & 0.1 \\
\hline
\end{tabular}

* MIC by agar dilution assay with nutrient agar plates.

** High resistant strain of Ps III to FR-900098.

sistance observed in this experiment suggested the close resemblance of the three antibiotic substances to each other and FR-900098.

The mode of action of the three antibiotics in inhibiting bacteria can be deduced from the fact that they induce the spheroplast formation of susceptible cells treated with lethal concentration of the drugs in hypertonic media.

FR-31564, FR-32863 and FR-33289 exhibit extremely low toxicity in experimental animals. $\mathrm{LD}_{50}$ value is larger than $5 \mathrm{~g} / \mathrm{kg}$ when administered intravenously to mice (ICR, 20 25 g).

\section{Discussion}

In the screening of antibiotics, the establishment of a method specifically detecting small amount of a particular substance is considered to be most important. In order to find inhibitors of cell wall synthesis, we have isolated a mutant of Pseudomonas aeruginosa supersensitive to nocardicin $\mathrm{C}$, which has only weak antibacterial activity ${ }^{4}$. Using the mutant, we elaborated a screening system and discovered a new phosphonic acid antibiotic, FR-900098 as described in the preceding paper ${ }^{1}$. Further screening using the mutant revealed that new three phosphonic acid antibiotics were produced in fermentation broths of Streptomyces.

The chemical structures of these antibiotics will be described in the following paper ${ }^{5}$. Before our finding of FR-31564 and FR-32863 in fermentation broth of Streptomyces lavendulae, chemists in our laboratories have already prepared a number of phosphonic acids structurally related to FR$900098^{2,6)}$. The antibiotics were among the analogues that have been prepared in an attempt to synthesize biologically more active compounds than FR-900098. FR-31564 and FR-32863 are N-formyl analogue of FR-900098 and its dehydro congener. FR-900098 has been determined as 3-(N-acetyl-Nhydroxy)aminopropylphosphonic $\mathrm{acid}^{2)}$. It is surprising that $\mathrm{N}$-formyl analogues have such stronger antibacterial activities than FR-900098 (Table 4).

The mutant Ps III is highly and specifically sensitive to $\beta$-lactam antibiotics. It is interesting that the mutant is also supersensitive to fosfomycin (unpublished data), another phosphonic acid antibiotic $^{7)}$, which is distinct from our antibiotics in its chemical and biological properties.

Discovery of these phosphonic acid antibiotics as well as that of nocardicins ${ }^{8)}$ proved the usefulness of the screening system with sensitive mutants. 


\section{References}

1) Okuhara, M.; Y. Kuroda, T. Goto, M. Okamoto, H. Terano, M. Kohsaka, H. Aoki \& H. Imanaka: Studies on new phosphonic acid antibiotics. I. FR-900098, isolation and characterization. J. Antibiotics 33: $13 \sim 17,1980$

2) Kamiya, T.; K. Нemmi, H. Takeno \& M. Hashimoto: Studies on phosphonic acid antibiotics. I. Structure and synthesis of 3-(N-acetyl-N-hydroxyamino)propylphosphonic acid (FR-900098) and its N-formyl analogue (FR-31564). Tetrahed. Lett. 1980: 95 98, 1980

3) Iguchi, E.; M. Okuhara, M. Kohsaka, H. Aoki \& H. Imanaka: Studies on new phosphonic acid antibiotics. II. Taxonomic studies on producing organisms of the phosphonic acid and related compounds. J. Antibiotics 33: 18 23, 1980

4) Hosoda, J.; T. Konomi, N. Tani, H. Aoki \& H. Imanaka: Isolation of new nocardicins from Nocardia uniformis subsp. tsuyamanensis. Agric. Biol. Chem. 41: 2013 2020, 1977

5) Kuroda, Y.; M. Okuhara, T. Goto, M. Okamoto, H. Terano, M. Kohsaka, H. Aoki \& h. Imanaka: Studies on new phosphonic acid antibiotics. IV. Structure determination of FR-33289, FR-31564 and FR-32863. J. Antibiotics 33: 29 35, 1980

6) Hashimoto, M.; K. Hemmi, H. Takeno \& T. Kamiya: Studies on phosphonic acid antibiotics. II. Synthesis of 3-(N-acetyl-N-hydroxyamino)-2(R)-hydroxypropylphosphonic acid (FR-33289) and 3-(N-formylN-hydroxyamino)-1-trans-propenylphosphonic acid (FR-32863). Tetrahed. Lett. 1980: 99 102, 1980

7) Hendlin, D.; E. O. Stapley, M. Jakson, H. Wallick, A. K. Miller, F. J. Wolf, T. W. Miller, L. Chalet, F. Kahan, E. L. Foltz, H. B. Woodruff, J. M. Mata, S. Hernadez \& S. Mochales: Phosphonomycin: A new antibiotic produced by strain of Streptomyces. Science 166: 122 125, 1969

8) Aoki, H.; H. SaKai, M. Kohsaka, T. Konomi, J. Hosoda, T. Kubochi, E. Iguchi \& H. Imanaka: Nocardicin A, new monocyclic $\beta$-lactam antibiotic. I. Discovery, isolation and characterization. J. Antibiotics 29: 492 500, 1976 